\title{
Can confounding by sociodemographic and behavioural factors explain the association between size at birth and blood pressure at age 50 in Sweden?
}

\author{
Ilona Koupilová, David A Leon, Denny Vågerö
}

\begin{abstract}
Study objective - To evaluate whether socioeconomic confounding explains the relationship between size at birth and blood pressure at age 50 .

Design - Cross sectional study with retrospectively collected data on size at birth.
\end{abstract} Setting - Uppsala, Sweden.

Participants - 1333 men born in 1920-24, and a subset of 615 men for analyses including early social circumstances.

Main outcome measures - Blood pressure measured after 10 minutes rest in supine position. Crude and adjusted effect measures were compared.

Main results - Controlling for sociodemographic characteristics at age $\mathbf{5 0}$, such as socioeconomic position, highest education achieved and marital status did not reduce the strength of the association between birth weight and systolic blood pressure at 50 years. In the total population, the slope of the body mass index adjusted relationship changed from $-3.4 \mathrm{mmHg} / \mathrm{kg}$ to $-3.5 \mathrm{mmHg} / \mathrm{kg}$ on additional adjustment for sociodemographic characteristics at age 50 (both p values $<0.01$ ). Controlling for behavioural characteristics at age 50, such as smoking and recent alcohol drinking, did not affect the relationship between birth weight and blood pressure at 50 . In the 615 men for whom information on sociodemographic circumstances in early life was available, adjustment for factors such as social class of the family, mother's marital status or area of residence, led to a slight reduction of the effect of birth weight on systolic blood pressure at age 50 . The slope of the body mass index adjusted relationship changed from $-2.8 \mathrm{mmHg} / \mathrm{kg}$ to $-2.6 \mathrm{mmHg} / \mathrm{kg}$ after additional adjustment for early life circumstances in the sample as a whole ( $p$ values 0.09 and 0.12). Simultaneous adjustment for sociodemographic characteristics at birth together with sociodemographic and behavioural characteristics at age 50 led to only a slight reduction of the effect of birth weight on systolic blood pressure at 50 years.

Conclusion - The strong inverse associations between birth weight and blood pressure among 50 year old Swedish men are highly unlikely to be explained by con- founding with socioeconomic circumstances at birth or in adult life.

(f Epidemiol Community Health 1997;51:14-18)

There is accumulating evidence that small size at birth is related both to higher mortality from cardiovascular disease and to higher levels of some cardiovascular risk factors, including raised blood pressure, impaired glucose tolerance and possibly even higher fibrinogen and higher total and low density lipoprotein cholesterol levels. ${ }^{1-5}$

A negative association between birth weight and blood pressure in middle age men has been previously reported from studies in UK and Uppsala, Sweden. ${ }^{467}$ In our study of 50 year old Swedish men, birth weight showed a stronger relation to systolic than to diastolic blood pressure. The association between low birth weight and high systolic blood pressure at age 50 was most pronounced in the men who were born at term, had high body mass index at 50 years and was present only in those who were tall as adults (had a height at 50 above the median of $176 \mathrm{~cm}){ }^{4}$

Confounding by continuities in socioeconomic disadvantage from birth to adulthood has been put forward as an explanation of the associations between perinatal conditions and adult morbidity and mortality. ${ }^{8-11}$ With respect to blood pressure, this could operate through continuing adversity in terms of lower socioeconomic position and its relation to adverse health related behaviour such as poor diet, heavy alcohol drinking or inadequate physical activity. To date, studies of the fetal origins of raised blood pressure in adult life have not adequately controlled for possible confounding effects of socioeconomic factors.

The analyses reported in this paper were undertaken to evaluate whether socioeconomic confounding can explain the strong relationship between size at birth and blood pressure that we have previously reported in this group of 50 year old Swedish men. ${ }^{4}$ We have used the same data as employed in our earlier paper, and have given particular attention to those subgroups in which the birth weight-blood pressure relationship appeared to be strongest, i.e. those in the top tertile of body mass index and those who were of above median adult height. 


\section{Methods}

The association between small size at birth and cardiovascular risk factors in later life has been studied in a population of 1333 men who were examined at the Institute of Geriatrics of the Uppsala University at the age of 50 (mean age at examination 49.6 years, range $48.6-51.1$ ) and whose birth records we were able to trace. This is a subgroup from a health survey that in 1970 recruited all men living in the municipality of Uppsala who were born between 1920 and $1924 .{ }^{12}$ The participation rate in the health survey was $82 \%$. The participants were examined in the morning after an overnight fast. Height (without shoes) was measured to the nearest centimetre and weight (in underpants) to the nearest kilogram. Body mass index (BMI) was calculated as weight (in $\mathrm{kg}$ ) / height (in $\mathrm{m})^{2}$. Blood pressure was measured once on the right arm to the nearest $5 \mathrm{mmHg}$ in the supine position after 10 minutes rest. ${ }^{13}$

Sociodemographic variables available for the analysis and related to the circumstances in adulthood came from questionnaires completed by the study subjects at age 50 and include three categories of social class previously used in official Swedish statistics, based on occupation: low (or manual workers), middle (or non-manual employees) and high social class (self-employed and professionals). ${ }^{14}$ The highest education achieved is classified in three categories - basic, secondary and university. Marital status is defined as married, single and divorced/widowed.

Adult behavioural characteristics included in the analysis were recent alcohol drinking (measured as consumption of a drink containing alcohol during the day before the examination), smoking (measured in four categories as non-smokers, $<10$ cigarettes/day, 10-19 cigarettes/day and $20+$ cigarettes/day). Complete data on all socio-demographic and behavioural characteristics at age 50 were available for 1031 subjects.

As described in more detail elsewhere, for $60 \%$ of the participants in the $1970-73$ health survey it was possible to trace their birth records including information on birth weight either in the Uppsala University Hospital or in archives of midwives records. ${ }^{45}$ Of the 1333 participants in the health survey with known birth details, 615 (46.1\%) were born in the Uppsala University Hospital, 334 (25.1\%) were born elsewhere in Uppsala county and 384 (28.8\%) where born elsewhere in Sweden.

Socio-demographic characteristics at birth were derived from the information given in the birth records from the Uppsala University Hospital and were thus available only for a subset of the study subjects. These were social class of the household based usually on the father's or if single the mother's occupation, maternal marital status (classified as married or unmarried), and the area of residence at birth (classified as urban or rural). A modified version of the Erikson-Goldthorpe classification has been used for the analysis of social class, ${ }^{15}$ and five categories were employed in the analysis. Unmarried women living in their parents' household were placed in a separate category known as 'house daughter'.

Linear regression was used to quantify the strength of the association between size at birth and systolic blood pressure (SBP) before and after adjustments for potential confounders. Analyses were carried out using the STATA statistical package. ${ }^{16}$ The potential confounding effect of the socio-demographic characteristics was evaluated in the whole sample, in a subgroup of obese subjects (highest tertile of BMI at 50), and also in those with adult height of more than $176 \mathrm{~cm}$. Separate analyses of men in the top BMI tertile and men of above median height are presented because these are the groups in whom the strongest association between birth weight and blood pressure at age 50 has been previously observed. ${ }^{4}$

The analyses for the study population as a whole were performed both with and without the adjustment for body mass index at 50 years. Birth weight was analysed both as a continuous and as a categorical variable. Though the effect of adjustment for each of the potential socioeconomic confounders in turn and for their combinations was partly dependent upon the approach used, the conclusions derived from the analyses were identical.

The data reported in the study were collected in a series of studies all of which were approved by the Uppsala University Ethics Committee.

\section{Results}

To evaluate the potential confounding effects of socio-demographic characteristics, we start by examining the associations of socio-demographic factors with birth weight and of sociodemographic factors with blood pressure. The results of these univariate analyses are shown in table 1.

\section{SOCIO-DEMOGRAPHIC AND BEHAVIOURAL} CHARACTERISTICS AND BIRTH WEIGHT

Of the socio-demographic indicators at birth, birth weight was most strongly related to maternal marital status. The mean birth weight of infants born to married mothers was $96 \mathrm{~g}$ (95\% CI $-5,196)$ higher than the mean birth weight of infants born to non-married mothers. Birth weight also varied appreciably by social class of the infant's family. Infants born to 'house daughters' had the lowest mean birth weight, infants born to women in farmers' households had the highest birth weight - the difference between these two groups amounting to $180 \mathrm{~g}$ (95\% CI 9, 350).

Men who were single at 50 years, were of a significantly lower mean birth weight than the rest of the study population (difference of $170 \mathrm{~g}$, $95 \%$ CI 67,273 ). Weight at birth also seemed to be related to the social class of the subjects at age 50. Men of the low and middle social class combined were $83 \mathrm{~g}(95 \% \mathrm{CI}-10,176)$ lighter than the men in the high social class. There was also a suggestion of a trend in mean birth weight increasing with higher education level, however, this trend was not statistically significant. 
Table 1 Univariate analysis of birth weight (g) and systolic blood pressure (SBP: $\mathrm{mmHg}$ ) at 50 years in relation to basic sociodemographic and behavioural characteristics at 50 years and at birth.

\begin{tabular}{|c|c|c|c|c|c|c|c|c|c|}
\hline \multirow[t]{2}{*}{$\begin{array}{l}\text { Sociodemographic and } \\
\text { behavioural characteristics }\end{array}$} & \multicolumn{3}{|c|}{$\begin{array}{l}\text { Data available in adulthood } \\
(n=1031)\end{array}$} & \multicolumn{3}{|c|}{$\begin{array}{l}\text { Data available at birth } \\
(n=594)\end{array}$} & \multicolumn{3}{|c|}{$\begin{array}{l}\text { Data available in adulthood and at birth } \\
(n=481)\end{array}$} \\
\hline & No & $\begin{array}{l}\text { Birth weight } \\
\text { Mean (SD) }\end{array}$ & $\begin{array}{l}S B P \\
\text { Mean }(S D)\end{array}$ & No & $\begin{array}{l}\text { Birth weight } \\
\text { Mean }(S D)\end{array}$ & $\begin{array}{l}S B P \\
\text { Mean }(S D)\end{array}$ & No & $\begin{array}{l}\text { Birth weight } \\
\text { Mean }(S D)\end{array}$ & $\begin{array}{l}S B P \\
\text { Mean }(S D)\end{array}$ \\
\hline \multicolumn{10}{|l|}{ Social class at 50 : } \\
\hline Low & 498 & $3584(517)$ & $133.5(17.7)$ & - & & & 246 & $3471(491)$ & $135.4(19.0)$ \\
\hline Middle & 407 & $3593(486)$ & $133.6(18.8)$ & & & & 208 & $3521(459)$ & $134.4(18.6)$ \\
\hline High & 126 & $3671(451)$ & $132.1(16.6)$ & & & & & $3578(423)$ & $136.5(15.7)$ \\
\hline $\mathrm{p}$ value trend & & 0.137 & 0.589 & & & & & 0.152 & 0.838 \\
\hline \multicolumn{10}{|l|}{ Education at 50 : } \\
\hline Basic & 750 & $3589(507)$ & $133.9(18.4)$ & - & & & 383 & $3488(480)$ & $135.2(19.3)$ \\
\hline Secondary & 194 & $3609(493)$ & $133.5(17.6)$ & & & & 84 & $3542(439)$ & $135.8(16.8)$ \\
\hline University & & 3649 (425) & $128.6(14.6)$ & & & & & $3539(505)$ & $126.4(8.2)$ \\
\hline $\mathrm{p}$ value trend & & 0.277 & 0.030 & & & & & 0.355 & 0.388 \\
\hline \multicolumn{10}{|l|}{ Marital status at 50 : } \\
\hline Married & 875 & $3611(483)$ & $133.4(18.0)$ & - & & & 404 & $3516(455)$ & $135.3(18.8)$ \\
\hline Single & 98 & $3444(535)$ & $132.9(17.3)$ & & & & 56 & $3400(513)$ & $134.2(18.1)$ \\
\hline Divorced/widowed & 58 & $3659(599)$ & $132.5(18.6)$ & & & & 21 & $3439(680)$ & $131.4(17.2)$ \\
\hline $\mathrm{p}$ value heterogeneity & & 0.004 & 0.897 & & & & & 0.193 & 0.610 \\
\hline \multicolumn{10}{|l|}{ Smoking at 50: } \\
\hline Non smoker & 895 & $3601(504)$ & $133.8(18.0)$ & - & & & 407 & $3502(482)$ & $135.7(18.9)$ \\
\hline$<10$ cigarettes $/ \mathrm{d}$ & 72 & $3610(436)$ & $128.7(16.4)$ & & & & 35 & $3486(425)$ & $127.6(12.1)$ \\
\hline $10-19$ cigarettes $/ \mathrm{d}$ & 41 & $3494(435)$ & $133.2(19.5)$ & & & & 28 & $3414(317)$ & $136.6(20.7)$ \\
\hline $20+$ cigarettes $/ \mathrm{d}$ & 23 & $3640(531)$ & $130.2(18.9)$ & & & & 11 & $3653(650)$ & $128.6(18.0)$ \\
\hline $\mathrm{p}$ value heterogeneity & & 0.566 & 0.112 & & & & & 0.552 & 0.053 \\
\hline \multicolumn{10}{|l|}{ Recent alcohol drinking at 50 : } \\
\hline No & 865 & $3599(497)$ & $133.1(18.2)$ & - & & & 404 & $3507(470)$ & $134.8(19.0)$ \\
\hline Yes & 166 & $3595(503)$ & $134.7(16.6)$ & & & & 77 & $3455(493)$ & $136.0(17.1)$ \\
\hline $\mathrm{p}$ value & & 0.933 & 0.269 & & & & & 0.379 & 0.602 \\
\hline \multicolumn{10}{|l|}{ Body mass index at 50 : } \\
\hline$<23.5 \mathrm{~kg} / \mathrm{m}^{2}$ & 332 & $3553(524)$ & $128.9(17.2)$ & 188 & $3449(525)$ & $130.9(16.6)$ & 155 & $3452(513)$ & $130.1(16.9)$ \\
\hline $23.5-25.9 \mathrm{~kg} / \mathrm{m}^{2}$ & 364 & $3599(465)$ & $132.4(17.1)$ & 208 & $3512(447)$ & $133.4(18.2)$ & 165 & $3501(443)$ & $133.9(18.0)$ \\
\hline$>=26.0 \mathrm{~kg} / \mathrm{m}^{2}$ & 335 & $3642(501)$ & $138.7(18.4)$ & 198 & $3527(464)$ & $141.5(21.7)$ & 161 & $3542(463)$ & $140.9(19.4)$ \\
\hline $\mathrm{p}$ value trend & & 0.020 & $<0.001$ & & 0.111 & $<0.001$ & & 0.090 & $<0.001$ \\
\hline \multicolumn{10}{|l|}{ Height at 50: } \\
\hline$<=176 \mathrm{~cm}$ & 550 & $3508(506)$ & $132.7(17.6)$ & 330 & $3387(444)$ & $134.1(18.8)$ & 265 & $3367(446)$ & $133.9(17.9)$ \\
\hline$>176 \mathrm{~cm}$ & 481 & $3701(466)$ & $134.1(18.3)$ & 264 & $3635(486)$ & $136.8(20.2)$ & 216 & $3661(457)$ & $136.4(19.5)$ \\
\hline $\mathrm{p}$ value & & $<0.001$ & 0.217 & & $<0.001$ & 0.098 & & $<0.001$ & 0.134 \\
\hline \multicolumn{10}{|l|}{ Family social class at birth: } \\
\hline "House daughter" & - & & & 38 & $3388(339)$ & $139.6(22.7)$ & 32 & $3429(346)$ & $138.4(23.4)$ \\
\hline Unskilled manual & & & & 230 & $3500(482)$ & $134.7(18.1)$ & 190 & $3508(483)$ & $134.9(18.7)$ \\
\hline Skilled manual & & & & 100 & $3542(478)$ & $135.1(18.9)$ & 77 & $3521(460)$ & $135.3(16.0)$ \\
\hline Farmer & & & & 85 & $3568(480)$ & $132.9(18.6)$ & 72 & $3578(487)$ & $133.3(18.4)$ \\
\hline Self-employed or non-manual & & & & 141 & $3448(501)$ & $136.7(21.4)$ & 110 & $3436(488)$ & $135.2(19.1)$ \\
\hline $\mathrm{p}$ value heterogeneity & & & & & 0.183 & 0.397 & & 0.298 & 0.783 \\
\hline \multicolumn{10}{|l|}{$\begin{array}{l}\text { p value neterogenely } \\
\text { Mother's marital status: }\end{array}$} \\
\hline Married & - & & & 488 & $3514(490)$ & $135.2(18.9)$ & 396 & $3518(484)$ & $134.8(17.6)$ \\
\hline Not married & & & & 106 & $3418(418)$ & $135.8(21.9)$ & 85 & $3410(413)$ & $136.2(23.0)$ \\
\hline $\mathrm{p}$ value & & & & & 0.061 & 0.771 & & 0.056 & 0.509 \\
\hline \multicolumn{10}{|l|}{ Area of residence at birth: } \\
\hline Urban & - & & & 370 & $3490(504)$ & $136.0(19.4)$ & 294 & $3481(492)$ & $135.6(18.0)$ \\
\hline $\begin{array}{c}\text { Rural } \\
\text { p value }\end{array}$ & & & & 224 & $\begin{array}{l}3509(435) \\
0.632\end{array}$ & $\begin{array}{l}134.2(19.5) \\
0.272\end{array}$ & 187 & $\begin{array}{l}3527(443) \\
0.299\end{array}$ & $\begin{array}{l}134.1(19.7) \\
0.371\end{array}$ \\
\hline $\mathrm{p}$ value & & & & & 0.032 & & & & \\
\hline
\end{tabular}

Neither smoking nor recent alcohol consumption as recorded at age 50 were significantly associated with birth weight in our data.

SOCIO-DEMOGRAPHIC AND BEHAVIOURAL CHARACTERISTICS AND BLOOD PRESSURE

Systolic blood pressure was strongly associated with education. There was a clear trend of systolic blood pressure decreasing as education level increased, the difference between those with basic and university education amounting to $5.2 \mathrm{mmHg}(95 \% \mathrm{CI} 1.2,9.2)$ in the sample as a whole and to $7.0 \mathrm{mmHg}(95 \% \mathrm{CI}-1.8$, 15.8) in those in the top BMI tertile. The differences in blood pressure between those with basic and university education, once adjusted for social class at 50 , became even greater $(10.9 \mathrm{mmHg}, 95 \% \mathrm{CI} 4.2,17.6$ in the whole sample; $15.8 \mathrm{mmHg}, 95 \% \mathrm{CI}-2.8,28.7$ in the obese subjects). On the other hand, when adjusted for education, the minor variation in blood pressure observed between the three social classes turned into a more substantial difference between the highest and the two lower social classes: the highest social class showed a $5.6 \mathrm{mmHg}(95 \% \mathrm{CI} 0.1,11.1)$ excess of SBP compared to the two lower social classes combined in the whole sample, $9.7 \mathrm{mmHg}$ $(95 \% \mathrm{CI}-0.2,19.6)$ in the obese.

There were also smaller differences in systolic blood pressure by other socio-demographic characteristics that did not achieve statistical significance. Being born into a farming household, for instance, was associated with a lower systolic blood pressure (table 1).

Alcohol consumption in the day before examination was associated with a slightly and non-significantly increased systolic blood pressure at 50 years (difference of $1.7 \mathrm{mmHg}, 95 \%$ CI $-1.3,4.7$, between those who had and had not an alcoholic drink on the day before the examination). Lower systolic blood pressure at 50 was found in smokers.

ADJUSTING FOR SOCIO-DEMOGRAPHIC AND BEHAVIOURAL FACTORS

Univariate adjustments for mother's marital status, social class at birth, place of residence at birth and highest education all reduced the strength of the association between low birth weight and high systolic blood pressure at 50, but removed only a minor part of the effect. Adjustment for social class at 50, recent alcohol drinking or smoking did not show any consistent effect on the strength of the association 
Table 2 Effect on systolic blood pressure ( $\mathrm{mmHg}$ ) (95\% CI) per $1 \mathrm{~kg}$ change in birth weight before and after adjustment for sociodemographic and behavioural characteristics

\begin{tabular}{|c|c|c|c|c|}
\hline & BMI top tertile & Height $>176 \mathrm{~cm}$ & Total population & Total population adjusted for $B M I$ \\
\hline \multicolumn{5}{|c|}{ Adult sociodemographic } \\
\hline No & 335 & 481 & 1031 & 1031 \\
\hline $\begin{array}{l}\text { Crude } \\
\text { Adjusted }\end{array}$ & $\begin{array}{l}-5.72(-9.63,-1.81) \\
-6.35(-10.33,-2.37)\end{array}$ & $\begin{array}{l}-4.02(-7.53,-0.52) \\
-4.19(-7.70,-0.67)\end{array}$ & $-2.58(-4.79,-0.38)$ & $-3.39(-5.55,-1.24)$ \\
\hline \multicolumn{5}{|c|}{ Birth sociodemographic } \\
\hline No & 198 & 264 & 594 & 594 \\
\hline Crude & $-5.75(-12.29,0.78)$ & $-5.30(-10.32,-0.28)$ & $-2.12(-5.40,1.15)$ & $-2.76(-5.93,0.42)$ \\
\hline Adjusted & $-5.04(-11.62,1.53)$ & $-4.06(-9.21,1.09)$ & $-1.86(-5.16,1.43)$ & $-2.55(-5.74,0.64)$ \\
\hline \multicolumn{5}{|c|}{ All sociodemographic and } \\
\hline No & 161 & 216 & 481 & 481 \\
\hline Crude & $-7.40(-13.86,-0.95)$ & $-4.17(-9.88,1.54)$ & $-1.34(-4.87,2.19)$ & $-2.07(-5.51,1.37)$ \\
\hline Adjusted & $-6.69(-13.45,0.06)$ & $-2.81(-8.74,3.11)$ & $-1.23(-4.80,2.34)$ & $-1.88(-5.34,1.57)$ \\
\hline
\end{tabular}

*Social class, education, marital status, recent alcohol drinking, smoking. †Family social class, mother's marital status, area of residence.

Table 3 Difference in systolic blood pressure at $50(\mathrm{mmHg})$ related to birth weight $<3250 \mathrm{~g}$, crude and adjusted for sociodemographic and behavioural factors*

\begin{tabular}{|c|c|c|c|c|c|c|}
\hline \multirow[t]{2}{*}{ Study group (n) } & \multicolumn{5}{|c|}{ Birth weight group (g) } & \multirow{2}{*}{$\begin{array}{l}\text { p value for } \\
\text { linear trend }\end{array}$} \\
\hline & $<3250$ & & $3250-$ & $3750-$ & $4250+$ & \\
\hline \multirow[t]{2}{*}{ BMI top tertile (161) } & Crude & 0 & $-3.52(-11.13,4.09)$ & $-8.05(-16.59,0.49)$ & $-8.00(-21.53,5.53)$ & 0.056 \\
\hline & Fully adjusted & 0 & $-1.30(-9.36,6.75)$ & $-6.59(-15.79,2.62)$ & $-6.25(-20.37,7.86)$ & 0.135 \\
\hline \multirow[t]{2}{*}{ Height above $176 \mathrm{~cm} \mathrm{(216)}$} & Crude & 0 & $-1.90(-9.21,5.42)$ & $-2.91(-10.64,4.83)$ & $-8.37(-18.28,1.53)$ & 0.119 \\
\hline & Fully adjusted & 0 & $-1.85(-9.44,5.73)$ & $-2.00(-9.96,5.96)$ & $-7.83(-18.31,2.66)$ & 0.209 \\
\hline \multirow[t]{2}{*}{ Total population (481) } & Crude & 0 & $0.65(-3.42,4.71)$ & $-1.44(-6.23,3.34)$ & $-3.54(-11.07,3.99)$ & 0.317 \\
\hline & Fully adjusted & 0 & $0.27(-3.84,4.38)$ & $-1.78(-6.64,3.08)$ & $-3.13(-10.79,4.53)$ & 0.314 \\
\hline \multirow[t]{2}{*}{ Total population, adjusted for BMI (481) } & Crude & 0 & $0.32(-3.62,4.26)$ & $-2.27(-6.92,2.37)$ & $-4.14(-11.45,3.16)$ & 0.176 \\
\hline & Fully adjusted & 0 & $0.10(-3.88,4.07)$ & $-2.63(-7.34,2.07)$ & $-3.46(-10.86,3.94)$ & 0.183 \\
\hline
\end{tabular}

* Social class, education, marital status, recent alcohol drinking and smoking at 50 years and social class of family, mother's marital status, and area of residence at birth.

between birth weight and blood pressure. However, adjustment for marital status at 50 slightly strengthened the association between birth weight and systolic blood pressure in those who were tall or obese at 50 .

Simultaneous adjustment for all the adult socio-demographic and behavioural characteristics (table 2) did not have any appreciable effect upon the strength of the association between birth weight and systolic blood pressure in the sample as a whole, however, among those in the top body mass index tertile, it led to an increase in the strength of the association.

Simultaneous adjustment for the three sociodemographic characteristics at birth consistently led to a slight decrease in the strength of the association between birth weight and systolic blood pressure at 50 , however the size of the change was moderate (table 2).

In a subgroup of subjects with information on social circumstances at birth and in adulthood and adult behavioural factors, simultaneous adjustment for all potential confounders did not have any appreciable effect upon the association between birth weight and blood pressure in the whole sample, and slightly reduced the strength of the association in those who were tall or obese at 50 years (table 2).

A similar impression is provided by table 3 , in which birth weight is treated as a categorical variable $(<3250,3250-, 3750-$ and $4250+\mathrm{g})$. Simultaneous adjustment for all early and adult social circumstances, smoking and recent alcohol drinking led to only a minor reduction in the difference in SBP at 50 between the two extreme categories of birth weight in all groups studied.

\section{Discussion}

Birth weight was most strongly determined by the marital status of the mother in our data. This finding is consistent with our analyses of determinants of birth weight among all persons born in the Uppsala University Hospital in 1920-24 (unpublished). The differences in mean birth weight seen by social class at birth also followed an expected pattern except perhaps for the relatively low mean birth weight of infants born to self-employed and non-manual families. It has to be stressed, however, that a majority $(71 \%)$ of the families in this combined category are families of lower grade non-manual workers. Dividing this category into a series of more homogeneous groups of families of low, middle, high non-manual class and selfemployed parents does not affect the results of this study with respect to the role of socioeconomic confounding in the relation between foetal growth and later blood pressure.

Mean birth weight of subjects born in the Uppsala University Hospital was lower than that of subjects born elsewhere in Uppsala county or the rest of Sweden. At the same time, the mean systolic blood pressure in subjects born in Uppsala county was higher than in those born elsewhere in Sweden. However, adjustment for geographical area of birth did not appreciably reduce the strength of the associations between birth weight and SBP, and the relations between birth weight and systolic blood pressure were still present in our data when the analysis was restricted to subjects born in Uppsala county or the Uppsala University Hospital in particular.

The blood pressure of 50 year old men in Sweden in early 1970s, as it appears from our 
data, was much more strongly determined by their education than by their current social class. This finding is broadly consistent with the results of two Swedish studies that explored the socioeconomic distribution of high blood pressure in the seventies. ${ }^{171}{ }^{18}$ In the study of men aged 25-75 performed in Skaraborg county, of all the socioeconomic factors studied such as marital status, place of residence, socioeconomic group (with 9 categories), occupation or branch of industry, education level showed the strongest correlation with blood pressure. ${ }^{17}$ In a study of 40-60 year old men from the Stockholm area, ${ }^{18}$ social group based upon amount of responsibility in the subject's job position and education were the strongest determinants of systolic blood pressure out of a set of sociological variables that included e.g. yearly income, conflicts or number of changes of job.

Despite the fact that the socioeconomic and behavioural factors are clearly related to both birth weight and blood pressure in adult life, the association between birth weight and blood pressure cannot be explained by confounding with these factors. The finding that the behavioural factors and social circumstances in adulthood in particular are unlikely to explain the negative association between low birth weight and high systolic blood pressure at 50 years may not be surprising in the light of the evidence that inverse associations between size at birth and blood pressure have been reported in children. ${ }^{19-24}$

We conclude that the socioeconomic confounding of the relationship between small size at birth and adult blood pressure is unlikely. We cannot exclude the possibility of some residual confounding in our data due to imprecise measurements of factors such as alcohol consumption or not sufficiently detailed classification of social position and other social circumstances both in infancy and adulthood. However, the very small changes in the size of the effect of size at birth on blood pressure after adjustment for the various socio-demographic characteristics or their combinations suggest that residual confounding is unlikely to be important.

The small reduction of effect when controlling for early childhood circumstances and strengthening of the effect when controlling for the adult social circumstances is an unexpected finding that requires further exploration. However, the strengthening of the effect of birth weight on blood pressure after simultaneous adjustment for education and social class at 50 years may be partly explained by the seeming interaction of the effect of education and social class upon birth weight, and blood pressure in particular. When stratified by educational level, birth weight seems to be regularly increasing with increasing social class, while the opposite is the case for systolic blood pressure. Once adjusted for the effect of education, the highest social class is actually associated with an in- crease in systolic blood pressure at age 50 in our data set.

Since we find that socioeconomic confounding is of minor importance for the relation between birth weight and systolic blood pressure at 50 years, our results point to the importance of the fetal environment. Whether the observed differences in blood pressure associated with birth weight are predictive of subsequent mortality is currently being investigated.

We would like to thank Lena Nyvall and Charlotte Freiman for tracing and collecting the obstetric data, Rawya Mohsen and Lars Berglund for their help with data management and Han Lithell and Paul McKeigue for comments on an earlier draft. This work was supported through grants from the UK Medical Research Council (Grant No 9306778), the Swedish Council for Social Research (Grant No 94-0157) and the Swedish Medical Research Council (Grant No B96-19X-05446-18B) During her work on this study IK was in receipt of a Royal Society postdoctoral research fellowship.

1 Hales CN, Barker DJP, Clark PMS, Cox LJ, Fall C, Osmond $\mathrm{C}$, et al. Foetal and infant growth and impaired glucose tolerance at age 64. BMF 1991;303:1019-22.

2 Barker DJP, Hales CN, Fall CHD, Osmond C, Phipps K, Clark PMS. Type 2 (non-insulin dependent) diabetes mellitus, hypertension and hyperlipidaemia (syndrome $\mathrm{X}$ ); mellitus, hypertension and hyperlipidaemia (syndrome

3 Barker DJP. In: DJP Barker. Mothers, babies, and disease in later life. London: BMJ, 1994. Chap 4

4 Leon DA, Koupilova I, Lithell HO, et al. Failure to realise growth potential in utero and adult obesity in relation to blood pressure in 50 years old Swedish men. BMF 1996; 312:401-6.

5 Lithell HO, McKeigue PM, Berglund L, Mohsen R, Lithell U-B, Leon DA. Relationship of birth weight and ponderal index to non-insulin-dependent diabetes and insulin response to glucose challenge in men aged $50-60$ years. BMF 1996;312:406-10.

6 Barker DJP, Bull AR, Osmond C, Simmonds SJ. Fetal and placental size and risk of hypertension in adult life. $B M \mathcal{Y}$ 1990;301:259-62.

7 Martyn CN, Barker DJP, Jespersen S, Greenwald S, Osmond C, Berry C. Growth in utero, adult blood pressure, and C, Berry C. Growth in utero, adult blood press

8 Ben-Shlomo Y, Davey Smith G. Deprivation in infancy or in adult life: which is more important for mortality risk? Lancet 1991;337:530-4.

9 Elford J, Whincup P, Shaper AG. Early life experience and adult cardiovascular disease: longitudinal and case-control studies. Int $\mathcal{F}$ Epidemiol 1991;20:833-44.

10 Davey Smith G, Ben-Shlomo Y. Early growth and clotting factors in adult life. $B M \mathcal{F} 1992 ; 304: 638-9$.

11 Paneth N, Susser M. Early origin of coronary heart disease the "Barker hypothesis"): Editorial. BMF 1995;310:4112 .

12 Hedstrand $\mathrm{H}$, Åberg $\mathrm{H}$. Treatment of hypertension in middle-aged men. A feasibility study in a community. Acta Med Scand 1976;199:281-8.

13 Skarfors ET, Selinus KI, Lithell HO. Risk factors for developing non-insulin-dependent diabetes: a 10 -year follow veloping non-insulin-dependent diabetes: a 10-year

14 Vågerö $\mathrm{D}$, Norell SE. Mortality and social class in Sweden - Exploring a new epidemiological tool. Scand $\mathcal{F}$ Soc Med 989;17:49-58.

15 Erikson R, Goldthorpe J. The constant flux. New York: Oxford University Press, 1992.

16 Stata Corporation. Stata reference manual: Release 3.1 Texas: College Station, 1993.

17 Haglund BJA. Geographical and socioeconomic distribution of high blood pressure and borderline high blood pressure in a Swedish rural county. Scand $\mathcal{F}$ Soc Med 1985;13. 53-66.

18 Theorell T, Lind E. Systolic blood pressure, serum cholesterol and smoking in relation to sociological factors and myocardial infarction. F Psychosom Res 1973;17:327-32.

19 Barker DJP, Osmond C, Golding J, Kuh D, Wadsworth MEJ. Growth in utero, blood pressure in childhood and adult life, and mortality from cardiovascular disease. $B M \Im$ adult life, and morta

20 Whincup PH, Cook DG, Shaper AG. Early influences on blood pressure: a study of children aged 5-7. BMF 1989, 299:587-91.

21 Whincup PH, Cook DG, Papacosta O. Do maternal and intrauterine factors influence blood pressure in childhood? Arch Dis Child 1992;67:1423-9.

22 Launer LJ, Hofman A, Grobbee DE. Relation between birth weight and blood pressure: longitudinal study of infants and children. BMf 1993;307:1451-4.

23 Whincup PH, Papacosta O, Cook DG. Initiation of hypertension in utero (letter). BMF 1993;306:584

24 Whincup P, Cook D, Papacosta O, Walker M. Birth weight and blood pressure: cross sectional and longitudinal relations in childhood. $B M \mathcal{F}$ 1995;311:773-6. 